\title{
AS DEMANDAS DE MEMÓRIA, O IMPASSE ACERCA DA HISTÓRIA OFICIAL DE PORTO ALEGRE E O PAPEL DA FOTOGRAFIA NAS COMEMORAÇÕES DO BI-CENTENÁRIO DA CIDADE, NO MANDATO DE LOUREIRO DA SILVA (1937-1943).
}

\author{
Olavo Ramalho Marques
}

\section{Introdução}

Esta monografia tem como tema algumas relações entre o espaço das grandes cidades e o tempo. O assunto é tratado a partir da análise de políticas públicas envolvendo a remodelação do tecido urbano de Porto Alegre, bem como políticas de gestão de memória, em um contexto histórico-social específico: o primeiro mandato de José Loureiro da Silva como prefeito de Porto Alegre (1937-1943). Esta foi uma época de grandes transformações sociais, econômicas, políticas e - mais importante no caso deste estudo - dos usos do espaço urbano e de suas formas de ocupação e vivência por parte dos moradores. A questão da gestão da memória e da historiografia como releitura do passado, realizada no intuito de se compreender o presente e se orientar o futuro, será abordada através de um livro de fotografias da cidade, lançado pela prefeitura municipal como parte das comemorações do bicentenário de Porto Alegre, no ano de 1940. As questões centrais que levanto acerca do período são: qual o estatuto das transformações urbanas em tal contexto? Qual o papel da gestão da memória nesse processo? A partir dessas formulações, buscarei discutir sobre as motivações simbólicas envolvidas na modernização da cidade, enfatizando a visão de cidade que estava sendo construída através do recurso fotográfico no livro lançado pela prefeitura.

Cabe deixar claro que este tema de pesquisa - as transformações urbanas - foi o que desenvolvi em meu Trabalho de Conclusão de Curso em Ciências Sociais, no ano de 2003. O objeto de estudo, entretanto, era diverso: abordei principalmente a realização de uma 
grande obra viária em Porto Alegre na época atual, a construção da $3^{\mathrm{a}}$ Perimetral - grande artéria urbana que corta mais de vinte bairros da cidade. E desenvolvi todo o meu trabalho de pesquisa estando vinculado a uma equipe de pesquisadores, o Banco de Imagens e Efeitos Visuais (BIEV): um projeto de pesquisa em antropologia urbana, cuja abordagem sobre a cidade é centrada na questão da imagem - tanto em relação à produção na pesquisa etnográfica, como forma de "estar em campo" e abordar os assuntos estudados, como em relação à análise de materiais que retratem aspectos e fragmentos da vida urbana em Porto Alegre. A proposta do Projeto BIEV é o da construção de coleções etnográficas sobre o patrimônio etnológico da cidade, compondo um museu virtual. Como se percebe, o tema do presente estudo é muito afim ao que vim desenvolvendo durante minha graduação (já que na equipe do Banco de Imagens e Efeitos Visuais cada pesquisador estuda assuntos específicos, relacionados ao tema central do projeto) e que ainda desenvolvo, agora cursando o mestrado em Antropologia Social; continuo ligado ao Projeto BIEV como pesquisador associado. A possibilidade de abordar o meu tema de interesse numa época diferente, agora sob a ótica das políticas de reescritura do passado, de representação do presente e de aceleração do tempo em direção ao futuro, me é extremamente satisfatória, e de grande utilidade para meu trabalho de pesquisa.

\section{Loureiro da Silva e as grandes transformações urbanas}

"Sou um bacharel urbanista. Adoro ver riscos de cidades projetadas. Especialmente da minha cidade, que tanto amo" ${ }^{1}$.

Essa frase, enunciada por José Loureiro da Silva, aparece estampada já na capa da biografia intitulada "Loureiro da Silva: o charrua", de autoria de Celito de Grandi. O autor, um jornalista, acompanhou de perto a carreira do ex-prefeito de Porto Alegre em seus dois mandatos, o primeiro deles no período entre os anos 1937 e 1943 e o outro entre 1960 e 1964. A frase de Loureiro da Silva, acima citada, remete a algumas de suas realizações, as profundas transformações no espaço urbano de Porto Alegre. A frase suscita, também, um questionamento: o que significa amar uma cidade e adorar ver os riscos que projetam sua transformação?

${ }^{1}$ DE GRANDI, Celito. Loureiro da Silva: o charrua. Porto Alegre: Literaris, 2002. 
O que está em jogo neste trabalho é uma reflexão acerca dos processos de destruição e reconstrução dos espaços da cidade, pautados, em geral, por um exacerbado mito do progresso ${ }^{2}$. Creio que seja consenso que habitamos, no meio urbano contemporâneo, espaços em permanente reformulação - renovações estas que acompanham mudanças tecnológicas, crescimento populacional, novas demandas de saneamento e higiene pública, entre outras inúmeras modificações sociais que incidem sobre as formas de ocupação dos espaços da cidade. Abordando a temática da modificação das formas de ocupação do espaço, necessariamente estamos lidando também com a dimensão temporal. E Loureiro da Silva, enquanto prefeito, é lembrado por habitantes, autoridades e acadêmicos como um dos grandes responsáveis pela modernização da cidade, por sua saída de uma situação colonial e arcaica e sua elevação ao estatuto de metrópole - ou ao menos pela preparação para isso. Além de ser recordada até hoje, a época da gestão de Loureiro da Silva caracterizou-se como fase de grandes mudanças na cidade de Porto Alegre, bem como pelos debates em torno da definição de uma versão oficial da história da cidade.

Observe-se que a data de início do primeiro mandato de Loureiro da Silva coincide, não por acaso, com o advento do Estado Novo de Getúlio Vargas. Loureiro foi nomeado prefeito pelo próprio Getúlio, que estabeleceu Daltro Filho como interventor federal após levar a cabo o golpe de estado, dissolver o congresso e os partidos políticos e revogar a constituição. Flores da Cunha, o então presidente eleito da província do Rio Grande do Sul, cercado pelas tropas de Daltro, foge e exila-se no Uruguai. Loureiro da Silva, advogado e deputado estadual, é nomeado para a prefeitura de Porto Alegre, governando com a câmara municipal fechada. Percebe-se que esta transição esteve longe de ser pacífica. O mesmo não ocorreu em seu segundo mandato: dessa vez, Loureiro da Silva foi eleito pela grande maioria da população porto-alegrense.

Entre as grandes realizações urbanísticas do primeiro mandato de Loureiro da Silva estão, segundo De Grandi ${ }^{3}$ o início de seis grandes obras viárias: a construção das avenidas Farrapos, 10 de Novembro (posteriormente denominada Salgado Filho), 3 de novembro (mais tarde André da Rocha); o prolongamento das avenidas Borges de Medeiros e João

${ }^{2}$ ECKERT, Cornelia e ROCHA, Ana Luiza Carvalho da. A retórica do mito do Progresso, 'Brasil, um país sem memória!’. Iluminuras: Série do Banco de Imagens e Efeitos Visuais, número 7. Porto Alegre: BIEV, PPGAS/UFRGS, 2000. 17f. 
Pessoa, além da retificação do antes tortuoso e lamacento Arroio Dilúvio. Percebe-se que as avenidas eram priorizadas em suas realizações. Loureiro da Silva, “ ...homem de confiança de Getúlio Vargas, poderia, valendo-se dessas condicionantes executar, soberano, o sonho de mudar Porto Alegre. Optou por outro caminho: criou o conselho do plano diretor"4. Este conselho, formado por 16 membros, entre os quais Pereira Paiva e Ubatuba de Faria, realizou diversos estudos sobre a malha viária da cidade e acabou por propor a ampliação das radiais existentes e a criação de novas vias deste tipo, além de projetar duas perimetrais - cortes profundos nesses eixos radiais. Firmavam, assim, para Porto Alegre, o sistema radiocêntrico cujo vértice é o centro insular, mais especificamente a ponta do gasômetro. As realizações das administrações anteriores, segundo o laudo do conselho, facilitavam o acesso ao centro ao alargar vias existentes e criar novas, porém apenas acumulavam problemas ao invés de solucionar os anteriores - o centro era cada vez mais repleto de engarrafamentos. A solução encontrada pelo conselho foi a descentralização urbana (então tida como uma das diretrizes da urbanística moderna), através da criação de novos centros e de perimetrais que desviassem do centro da cidade parte do tráfego de veículos - o centro deveria deixar de ser rota obrigatória para quem se deslocava entre partes da cidade. $\mathrm{O}$ resultado do trabalho desse conselho foi o anteprojeto do Plano Diretor de Melhoramentos da Capital. O novo projeto pautava-se em diretrizes do antigo Plano de Melhoramentos de João Maciel (Plano Maciel, de 1914), que inspirou os feitos de Otávio Rocha e Alberto Bins, centrando-se na reforma do centro colonial. O novo plano incluía, além de certas diretrizes do Plano Maciel, idéias de Arnaldo Gladosh (arquiteto trazido do Rio de Janeiro para propor projetos de renovação da trama viária porto-alegrense, influenciado pelos ideais do urbanista francês Alfred Agache), além dos estudos do conselho do Plano Diretor, que realizou um amplo censo sobre as características de Porto Alegre e de sua população, com vistas a enquadra-la “...dentro das concepções científicas da urbanística moderna". 5

Loureiro da Silva, além do destaque regional, teve ainda grande influência na esfera federal: sugeriu a Getulio Vargas a criação da Lei das Desapropriações, que favorecia as remoções de população para a construção de obras viárias nas cidades brasileiras; propôs ainda que se tornasse obrigatórios os planos diretores para cidades com mais de quarenta

\footnotetext{
${ }^{3}$ DE GRANDI, CELITO. Idem.

${ }^{4}$ DE GRANDI, Celito. Idem, p. 103.

${ }^{5}$ Idem, p. 99.
} 
mil habitantes. No prefácio da obra de Celito de Grandi, intitulado "O homem e seu drama”, Luis Antônio de Assis Brasil escreve: "Todas as cidades possuem seus agentes iluminados: estão nesse rol o Barão Haussmann, que abriu os grandes bulevares de Paris, Pereira Passos, que transformou o Rio de Janeiro numa metrópole moderna [...] e, ainda, Juscelino Kubitscheck, que idealizou e fez construir Brasília. Porto Alegre tem Loureiro da Silva. Para todos nós, porto-alegrenses natos ou naturalizados, ele significa a Av. Farrapos, a João Pessoa, a Salgado Filho. É natural que adotemos as expressões visíveis como as mais significativas de uma administração"6. Veja que o escritor equipara Loureiro da Silva a Pereira Passos e a Haussmann, em suas escalas e cidades respectivas, como os homens iluminados - pela razão técnica? - que construíram cidades modernas. Conforme atesta o autor, estes processos de transformação são visíveis em grandes metrópoles do mundo todo. Paris destaca-se como um referencial. Barão Haussmann foi o prefeito que se incumbiu de transformar a Paris Medieval na Paris moderna, em fins do séc. XIX. A reforma Passos, conforme Mello (1997), no Rio de Janeiro (prefeito Pereira Passos, 1902 - 1906) veio no sentido de transformar a cidade imunda em cidade higiênica, moderna e capitalista. Para este mesmo autor, as cirurgias urbanas encontraram "grande acolhida entre as elites modernizadoras do país, que jamais hesitaram em enfrentar qualquer apego a antigos valores, a antigas 'usanças urbanas', taxando sempre este comportamento como um indicador de conservadorismo, de atraso, de subdesenvolvimento" (ABREU apud MELLO, 1997). Entretanto, quando se consolidam drásticas transformações urbanas como as que processava Loureiro da Silva em Porto Alegre, na dec. de 40, os impactos sobre a população são inevitáveis. Quais seriam, no referido contexto, as conseqüências da realização de grandes obras de reestruturação viária da cidade de Porto Alegre, que necessariamente implicavam na destruição de antigas formas de ocupar o espaço da cidade?

\section{Sobre o tempo: a construção social do passado}

Charles Monteiro, em sua tese de doutoramento em história, intitulada "Porto Alegre e suas escritas: histórias e memórias"7 , aborda o fenômeno da construção social da

\footnotetext{
${ }^{6}$ Idem, prefácio ( $\left.\mathrm{s} / \mathrm{n}\right)$.

${ }^{7}$ MONTEIRO, Charles. Porto Alegre e suas escritas - histórias e memórias. Tese de Doutorado em história. PUC-SP: São Paulo, 2001.
} 
memória sobre a cidade de Porto Alegre através da historiografia oficial e de relatos de cronistas que descreviam o ambiente urbano. Segundo o autor, trata-se de elaborações que necessariamente privilegiam certos sujeitos, espaços e tempos, iluminando-os, em detrimento de outros que, relegados, permanecem obscuros. Em sua tese, enfoca as mudanças nos espaços urbanos e nas formas de experienciar a cidade durante os mandatos de Loureiro da Silva e Tompson Flores (1969-1974). Para ele, a cidade é composta de tempos plurais, ritmos diversos e muitas formas de ocupar os espaços; os períodos enquadrados em sua análise, por conta das grandes transformações espaciais, políticas e sociais, seriam característicos tempos acelerados. Sob este prisma, Charles Monteiro aborda as formas através das quais os intelectuais, em seus círculos de sociabilidades e seus elos com os poderes públicos, elaboraram a memória coletiva e a história da cidade, reescrevendo o passado desse corpo coletivo.

Segundo Charles, em 1940, Porto Alegre contava com cerca de 350.000 habitantes. Utilizando-se de variadas fontes, como jornais, revistas, livros e documentos, verifica que a cidade sofria um enorme crescimento populacional, econômico, industrial, nos índices de construção civil, na saúde pública, no saneamento, no movimento portuário, no transporte urbano e na urbanização - construção e alargamento de ruas e avenidas, calçamento e etc. Caracterizavam a paisagem urbana da época grandes obras viárias como a canalização do Arroio Dilúvio, a abertura da av. Farrapos (segundo De Grandi ${ }^{8}$ principal marca da administração de Loureiro da Silva, símbolo de ousadia, na época, por conta de suas dimensões), o princípio da verticalização do centro, o crescimento de áreas verdes, praças e parques, a reformulação e construção de novos prédios públicos. Tais processos, já iniciados nas administrações municipais anteriores, de Otávio Rocha (1924-1928) e de Alberto Bins (1928-1937), intensificaram-se com o governo de Loureiro da Silva (até 1943). Tal expressivo quadro de mudanças implicava em perdas referenciais para a população, conforme se desenrolava o processo de metropolização.

Ainda segundo Charles Monteiro, esses períodos de tempo acelerado trariam como consequiência demandas de memórias, caracterizando um jogo complexo entre lembrança e esquecimento: nesse sentido, as elites letradas seriam responsáveis por interpretar as experiências sociais urbanas e a herança cultural, sugerindo projetos de futuro. Através de

\footnotetext{
${ }^{8}$ DE GRANDI, Celito. Idem.
} 
museus, monumentos, disciplinas escolares, tombamentos, escritas e etc, se supriria tais demandas. De acordo com Le Goff (1994, p. 31), "Elaborar um fato histórico é construílo.[...] Só há fato ou fato histórico no interior de uma história-problema”. Para Bachelard (1988), a memória não é uniforme e uni linear; ao contrário, procede por saltos através de núcleos temporais erigidos ao redor de eventos significativos. E não se pode relembrar o passado sem articulá-lo em um tema afetivo necessariamente presente. Há, em todos os casos, de releitura do passado, certos espaços, sujeitos e tempos enfocados, enquanto outros permanecem na penumbra e não são trazidos à luz.

No caso deste trabalho, em termos das políticas de gestão da memória, será analisado um interessante material contido num álbum comemorativo do bicentenário da colonização de Porto Alegre, lançado pela prefeitura municipal no ano de 1940 (mandato de Loureiro da Silva), composto quase exclusivamente de fotografias - exceto parágrafos introdutórios de autoria de renomados intelectuais - que retratam algumas feições específicas da cidade na época. A questão do bicentenário da cidade é um dos temas centrais desse trabalho, sendo abordado tanto no livro de Celito de Grandi como na tese de Charles Monteiro. Houve e ainda há, apesar de aparentemente resolvida, uma grande polêmica envolvendo tais comemorações, pelo fato de não se ter claro qual a data inicial a partir da qual seriam contados os anos idos desde o início da cidade. Alguns eram favoráveis à data de concessão da Sesmaria de Sant'Ana a Jerônimo de Ornelas, por volta de 1740 - entre eles Loureiro da Silva, descendente direto de Ornelas, o primeiro colonizador das terras onde se formou cidade de Porto Alegre. Para estes, o bicentenário deveria ser comemorado, portanto, em 1940. Outros defendiam como data de fundação a ocasião do estabelecimento dos casais açorianos, primeiros habitantes do território portoalegrense, no então Porto do Dornelles, o porto da cidade de Viamão, em 1752. Outros ainda defendiam que só poderia ser considerado o início da cidade a partir do momento em que o governo central do Brasil reconheceu Porto Alegre como freguesia em 1772. Isto se deu um ano antes da capital da província ser transferida de Viamão (onde esteve nos anos anteriores, depois da antiga capital, Rio Grande, ser invadida pelas tropas espanholas) para Porto Alegre, por conta de sua localização estratégica e privilegiada formação geográfica cercada de morros à beira de um imenso lago - que contribuía para a defesa do território ameaçado pelas investidas marciais das colônias espanholas, e para o transporte fluvial. A 
região sul do Brasil, tardiamente colonizada, era alvo de uma permanente disputa entre as coroas portuguesa e espanhola.

Conforme Charles Monteiro ${ }^{9}$, o palco oficial dos debates acerca da escritura da história gaúcha e porto-alegrense, incluindo a questão da centelha inicial a partir da qual a cidade Porto Alegre se formava, era, além dos círculos de sociabilidade dos intelectuais (como o antigo Café Colombo e outros cafés, bares e cabarés, ale da Livraria do Globo), o Instituto Histórico e Geográfico do Rio Grande do Sul (IHGRS). Este foi o principal local de produção e legitimação dos discursos históricos sobre a formação do Rio Grande do Sul e de Porto Alegre. E, no contexto da dec. de 1940, com o processo de reurbanização somado a um estado forte, surgia a necessidade de uma releitura da história e da memória para que se pudesse compreender o que se passava no presente. E Walter Spalding, coordenando a biblioteca municipal, responsável pela organização de documentos históricos, desenvolveu uma forte parceria com Loureiro da Silva. Ambos elaboraram, juntos, novas formas de percepção do passado, de modo que se justificasse a importância das obras realizadas pela administração municipal.

Havia no referido período, segundo Charles Monteiro, uma política de gestão da memória. E, com o respaldo dos intelectuais, Loureiro acaba por mudar a data de comemoração do Bicentenário de Porto Alegre para a década de 1940, estabelecendo-se como marco inicial do surgimento da cidade o início de sua colonização pela concessão das terras ao sesmeiro - e não o início da povoação ou da construção da cidade. Percebe-se que tal manobra política implica na manipulação de um impasse científico da história oficial em prol de uma comemoração que marcasse o governo de Loureiro da Silva. Manipula-se a própria visão do passado da cidade em função de um jogo político. Assim, Loureiro funda o Departamento Central de Festejos do Bi-centenário, da Prefeitura Municipal. Esse departamento lança em 1940, um livro fundamental que se torna, ainda de acordo com Monteiro, a matriz historiográfica sobre a cidade: "Porto Alegre: biografia duma cidade" ${ }^{10}$, sob a direção de Walter Spalding, como dito então coordenador do IHGRS e diretor do Arquivo e Biblioteca da Prefeitura Municipal. Este é um livro de quase setecentas páginas, que conta em detalhes sobre clima, relevo, geografia da cidade, índices de crescimento,

\footnotetext{
${ }^{9}$ MONTEIRO, Charles. Idem.

${ }^{10}$ SPALDING, Walter (coord.). Porto Alegre Biografia Duma Cidade. Departamento central dos Festejos do Bicentenário. Porto Alegre: Of. Graf. Da Livraria do Globo, 1940.
} 
construção civil, nascimentos e óbitos, relatos de cronistas, capítulos específicos sobre história, urbanização e etc. Conta ainda com cerca de duas mil imagens, entre fotografias, têmperas, aquarelas, óleos, gravuras a bico de pena e outras técnicas. Trata-se de um material extremamente complexo, que extrapolaria incrivelmente o espaço deste trabalho. Por conta disso, torna-se mais adequado investirmos na análise de outro livro, também concernente aos festejos do bi-centenário, lançado pelo departamento acima citado no mesmo ano, porém de outra natureza: a obra "Porto Alegre, Retrato de uma cidade"11, que contém em sua introdução relatos curtos de intelectuais acerca de impressões sobre cidade de Porto Alegre e, principalmente, cerca de 65 páginas dedicadas a divulgar imagens da cidade através de fotografias e montagens fotográficas de autoria de W. Hoffmann Harnisch Filho.

\section{O discurso através de imagens da cidade}

Em primeiro lugar, é necessário salientar que um livro de fotografias comemorativo do aniversário de Porto Alegre é um importante construto cultural, que transpira certas visões do mundo e da cidade, certos prismas ideológicos e noções sobre o espaço, o tempo e as ações transformadoras do tecido urbano. Pretendemos, aqui, seguindo os pressupostos de Baxandall $^{12}$ ligar a arte e os objetos artísticos ao contexto social em que está inserido, resgatando - tanto quanto possível - certo "olhar de época".

Segundo Etienne Samain, "toda fotografia é um olhar sobre o mundo, levado pela intencionalidade de uma pessoa, que destina uma mensagem visível a outro olhar, procurando dar significado a este mundo"13. Conforme Achutti, o olhar implica em capacidade de simbolização, criação e leitura de imagens. Não sendo puramente individual, o olhar do fotógrafo também é determinado social e conjunturalmente. Para Baxandall a cultura fornece os instrumentos mentais que permitem ao indivíduo organizar sua experiência visual. Assim sendo, o artista sempre produz imerso em determinados estilos

\footnotetext{
${ }^{11}$ SPALDING, Walter (coord.). Porto Alegre, Retrato de uma Cidade. Departamento central dos Festejos do Bicentenário. Porto Alegre: Of. Graf. Da Livraria do Globo, 1940.

${ }^{12}$ BAXANDALL, Michel. O olhar renascente - Pintura e experiência social na Itália da Renascença. São Paulo: Ed. Paz e Terra, 1991.

${ }^{13}$ SAMAIN, Etienne, In: ACHUTTI, Luiz Eduardo Robinson. Fotoetnografia: um estudo de antropologia visual sobre cotidiano, lixo e trabalho; Porto Alegre: Tomo Editorial; Palmarinca, 1997. P. 36.
} 
cognitivos e convenções representacionais, que permitem ao público interpretar sua criação. Assim sendo, cabe refletir sobre o lugar da fotografia em nosso meio social e seus usos no contexto do mandato de Loureiro da Silva, em que se buscava traçar a imagem de uma cidade que completava seus duzentos anos - conforme a manipulação do referido impasse histórico.

Segundo Arlindo Machado ${ }^{14}$ nossa sociedade credita objetividade à fotografia, tomando-a como um "espelho do mundo" dotado de memória - dessa idéia advém o título de sua obra, A Ilusão Especular. É, entretanto, para o autor, um código representacional que permite o efeito de realidade a que a imagem fotográfica induz. Esconde-se o trabalho de criação - e, a partir disso a interpretação e construção da realidade - do artista através do respaldo supostamente objetivante da máquina. Não é à toa que a lente da câmera é denominada objetiva. Conforme Aaron $\operatorname{Scharf}^{15}$, a fotografia, desde o anúncio de sua invenção, em 1839, surpreendeu pela delicadeza tonal e uniformidade que permitia. Tratava-se de uma época em que se creditava à eficácia das máquinas uma virtude essencial. O tipo de imagem que o novo aparelho permitia, entretanto, não surgiu no vácuo. Os convencionalismos que propunha não eram completamente novos, mas aproximavam-se bastante do modelo pictórico em voga (em elementos tais quais a escala de posturas, as tonalidades, a instantaneidade na representação de gestos e etc.). Para Machado, enfatiza-se a captura do referente no processo fotográfico. A construção e codificação da imagem, porém, sempre existe, e o papel do fotógrafo é ativo em tal processo. Não há, assim, realidade que permaneça intacta na fotografia. Nesse sentido deve-se questionar o que aparece nas imagens fotográficas e o modo através do qual os elementos que abarca são registrados. É com tal intuito que nos debruçaremos sobre as fotografias contidas no álbum "Porto Alegre, Retrato de uma cidade".

Segundo Kossoy (op. cit.) as elites brasileiras utilizaram-se largamente desta forma de representação no intuito de divulgar imagens cujos códigos culturais e estéticos transmitiam a idéia de modernidade, esplendor e progresso. É justamente a imagem da fotografia como captura imparcial da realidade, que Kossoy busca desconstruir, salientando o processo de construção de realidades envolvido na produção de imagens. Conforme o

\footnotetext{
${ }^{14}$ MACHADO, Arlindo. A Ilusão Especular: Introdução à fotografia. São Paulo: Brasiliense, 1984.

${ }^{15}$ SCHARF, Aaron. Arte y Fotografía. Madrid: Alianza Editorial, 1994.
} 
autor, as ideologias utilizam-se da fotografia como modo de veicular determinadas idéias. As imagens, assim, são fontes históricas multidisciplinares: não sendo espelhos fiéis dos fatos ocorridos, comportam, como toda imagem, ambigüidades e significados implícitos, omissões calculadas, pensadas.

No que diz respeito ao livro "Porto Alegre, Retrato de uma Cidade", buscarei, além da análise de certas fotografias em especial, desvendar um sentido de conjunto que permite a reunião de cerca de mais de sessenta e cinco documentos em uma edição comemorativa que supostamente traça um retrato da cidade de Porto Alegre. Sabendo-se que a cidade é um todo complexo, heterogêneo, diverso e fragmentado, composto de uma pluralidade de ritmos e pulsações, que se compõe de uma sobreposição de camadas de tempo ${ }^{16}$ e configurações espaciais, e tendo em vista que a fotografia consiste num fragmento selecionado do real, pretende-se questionar qual é a imagem de cidade que este retrato - ou este conjunto de retratos - constrói. Cabe, primeiramente, a descrição do material e algumas reflexões conforme se avança na exposição.

Apesar do conteúdo do livro ser composto de fotografias, sua capa, em tecido, contém desenhos de autoria de Ernst Zeuner, que retratam várias construções da cidade sobrepostas, contendo belos prédios coloniais como a catedral metropolitana e o mercado público, além de uma igreja, lado a lado com grandes arranha-céus, imensos prédios de apartamentos. São desenhos que, no entanto, aproximam-se muito da representação fotográfica, buscando um retrato fiel do referente. E as imagens são sobrepostas sem uma preocupação com relações de proporcionalidade e perspectiva. São aspectos materiais da cidade bricolados em uma mesma página. Já por essa imagem, podemos inferir sobre o conteúdo do livro, que aborda principalmente aspectos agradáveis da cidade, como vistosos prédios, largos, praças e parques. O que chama mais a atenção, entretanto, é o conteúdo semântico da representação da capa: antigos aspectos materiais e arquitetônicos em conjunto com novos e modernos edifícios, feições de uma cidade em crescimento.

\footnotetext{
${ }^{16}$ ECKERT, Cornelia e ROCHA, Ana Luiza Carvalho da. A retórica do mito do Progresso, 'Brasil, um país sem memória!'. Iluminuras: Série do Banco de Imagens e Efeitos Visuais, número 7. Porto Alegre: BIEV, PPGAS/UFRGS, 2000. 17f.
} 
Este jogo entre modernidade e tradição será uma constante no decorrer da obra, o que se torna transparente já na página de rosto do livro, que contém uma fotografia que mostra, em primeiro plano, um homem vestido com as roupas tradicionais da figura do gaúcho, "pilchado" como se diz, com chapéu na cabeça, lenço no pescoço, colete, bombachas e botas, manipulando uma faca provavelmente picando fumo de rolo descontraidamente recostado sobre barris em um porto, com embarcações ancoradas à margem, e um grande edifício de cerca de dez andares ao fundo. A meu ver, essa imagem expressa um tratamento estético da vida urbana que une as inovações decorrentes das transformações sociais e espaciais da cidade com os seus aspectos arcaicos e tradicionais - no caso, expressos através da figura arquetípica do gaúcho.

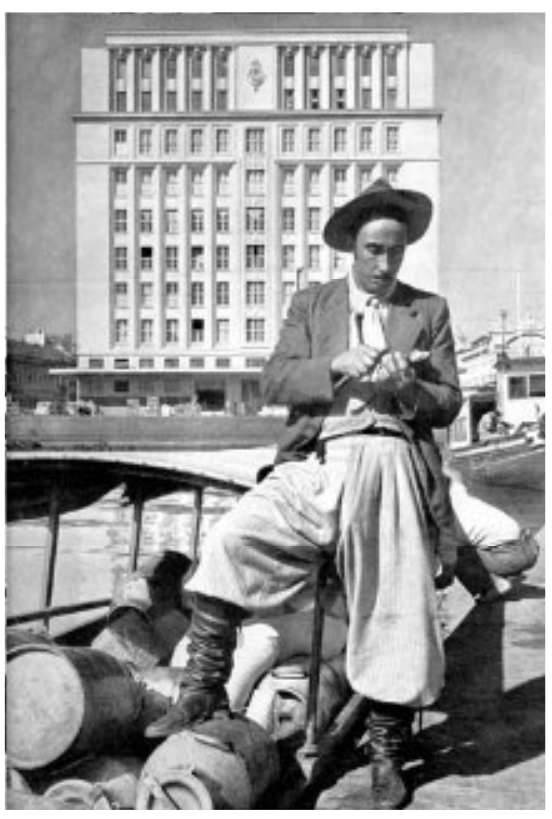

A introdução do livro, que contém o título "História Sintética da Cidade", de autoria de Walter Spalding, inicia da seguinte maneira:

"Pôrto Alegre antes de ser o que hoje é, foi simples fazenda ou estância, propriedade de Jerônimo de Ornelas Menezes e Vanconcelos que nela se instalou com sua família e a de seus agregados, iniciando, assim, sua colonização.

Esse povoado, clandestino desde 1732, foi confirmado pela carta de sesmaria de 5 de novembro de 1740, data considerada como início de Porto Alegre.

Em 1747 tiveram lugar os primeiros atos religiosos, sob a invocação de São Francisco, no então Pôrto de Viamão

No ano de 1752 chegaram os primeiros casais açorianos, em número de 55, iniciando-se, assim, o povoamento oficial recebendo o nome de São Francisco do Pôrto dos Casais.

Marcelino de Figueiredo (nome adotado por Manoel Jorge Gomes de Sepúlveda), governador do Rio Grande, iniciou, em 1770, a urbanização do povoado do Pôrto dos Casais e, em 1773, a 24 de julho, dando-lhe o nome de Nossa Senhora da Madre de Deus de Pôrto Alegre, transportou para êle a Capital que esteve no Rio Grande (1737-1763), no Rio Pardo (1763-1766) e no Viamão (1766-1773).

Teve, então, Pôrto Alegre vida nova, passando de Freguesia á categoria de vila a 23 de abril de 1790 mas instalada somente a 11 de dezembro de 1810.”

[...]

Foi durante o período republicando que Pôrto Alegre mais se desenvolveu, mas na administração Otavio Rocha teve início a sua remodelação, remodelação que o bacharel José Loureiro da silva está completando, fazendo da cidade velho uma cidade nova, alegre, sorridente, imponente." 
Nessa breve introdução, relatando superficialmente a história da cidade, Spalding retrata as concepções da historiografia oficial, como "voz do conhecimento", sem sequer mencionar as tensões e ambigüidades envolvidas na definição de um marco inicial a partir do qual Porto Alegre se desenvolveu. Por que não definir o momento inicial como a época em que Jerônimo de Ornelas e seus afins se estabeleceram no território que mais tarde abrigaria Porto Alegre, ou o momento em que chegaram os primeiros colonos ou ainda a data de reconhecimento de Porto Alegre como freguesia perante o governo central? Tal questão não é abordada, sendo apenas informada a data oficial então estabelecida, data esta que foi alterada anos mais tarde, depois de diversos debates nos círculos intelectuais, quando se estabeleceu o reconhecimento da Freguesia como data inicial - Porto Alegre teve, então, na década de 1970, uma nova comemoração do bicentenário.

Após o breve histórico acima relatado, surge um tópico intitulado "Impressões de Intelectuais contemporâneos", onde ilustres figuras porto-alegrenses como Erico Veríssimo, Mario Quintana, Nilo Ruschel e outros escrevem alguns comentários sobre Porto Alegre. Destacam-se, sob o foco de interesse desse estudo, alguns dizeres em especial. Mário Quintana afirma: "O que me agrada em Porto Alegre (perdoem-me os supersticiosos do Progresso com P grande) são as características que ainda conserva de cidade pequena: tudo quasi uma família só, tudo conhecido, encontros fáceis e pouquíssimos de cosmopolitismo e arrivismo, por enquanto... Mas até quando?" É interessante refletirmos sobre o porquê de uma declaração como essa estar contida na introdução de um livro que comemora o aniversário da cidade e busca mostrar seu crescimento, as avenidas, os bondes, parques e praças. O fato é que o livro manifesta não somente visões sobre o "progresso" da cidade, mas também imagens de lugares de feições arcaicas, de tipos populares e práticas sociais singulares.

A partir da introdução, o livro é dividido em alguns temas, não necessariamente ordenados linearmente, pois as fotografias sobre os diferentes assuntos encontram-se mescladas. No índice, situado na última página da obra, encontram-se as seguintes divisões: 20 páginas dedicadas a imagens que tratam sobre o "Urbanismo" (fotografias de avenidas, praças, parques e jardins, prédios públicos, prédios do bairro universitário, novas construções, o aeroporto, escolas e teatros, entre outras construções). Trata-se de imagens onde se destacam belos construtos, amplas avenidas, aprazíveis perspectivas da paisagem 
urbana, panoramas da verticalização do centro da cidade e etc.; 15 páginas são dedicadas a "Monumentos Históricos e Culturais", onde se mostra Igrejas, detalhes ornamentais de certos edifícios, prédios históricos, a Ponte dos Açorianos, estátuas e monumentos dedicados a figuras importantes na história do Rio Grande do Sul como o General Osório e Bento Gonçalves; 11 páginas são dedicadas ao "Portoalegrense e sua vida", onde são retratados estudantes, trabalhadores, músicos, esportistas, tipos populares e operários; 7 páginas são dedicadas a "Folklore e Arrabaldes", contendo paisagens à beira rio, antigas casas da aristocracia rural, o fazer artesanal de pescadores, além de imagens de um típico divertimento popular, as rinhas de galo. Por fim, duas páginas contêm "O Adeus da Cidade Sorriso", onde mostra-se a cidade e o porto à noite.

Fica claro, através das divisões acima citadas, que foram privilegiados documentos sobre a reurbanização da cidade, sua verticalização, a construção de avenidas e parques, aspectos de suas novas e belas feições, ressaltando as realizações dos prefeitos que se incumbiam de reconstruí-la e moderniza-la. Se somarmos o primeiro ao segundo tópico - já que são compostos de imagens cujo enquadramento seleciona visões de paisagens, prédios e construtos, onde a figura humana, quando aparece, encontra-se inserida ou diluída na paisagem - veremos que quase dois terços do livro dedicam-se a construir uma visão de cidade higienizada, saneada e reformulada. Cerca de dezoito páginas mostram aspectos do que poderíamos considerar uma paisagem humana porto-alegrense, retratando tipos populares e habitantes da cidade - pouco mais da metade do número de páginas dedicadas ao urbanismo e aos monumentos. $\mathrm{O}$ fato de se privilegiar imagens do primeiro tipo indica a busca de construção de um projeto estético de cidade, onde as avenidas e os belos prédios históricos constroem um olhar de época sobre Porto Alegre.

Depois de traçado esse panorama geral dos assuntos abordados nas imagens contidas no livro, cabe analisar algumas imagens mais especificamente, bem como refletir sobre elementos tais quais diagramação/paginação, montagem e sequiência de imagens. Depois dos relatos dos intelectuais, a primeira fotografia do livro, que ocupa toda a página 9, consiste num panorama obtido da sacada de um edifício alto, de onde se vê uma ampla avenida, a Borges de Medeiros - ocupada por bondes, carros, transeuntes e uma ou outra charrete - em cujos limites erguem-se alguns altos edifícios, dois deles com mais de dez andares,. Na legenda, situada na parte inferior esquerda da página lê-se: A avenida Borges 
de Medeiros - um traço moderno da cidade. Na margem inferior direita, encontra-se a mesma legenda escrita em língua inglesa, o que transparece o fato de o livro não ser produzido apenas com vistas a atingir o mercado interno, mas também países e consumidores estrangeiros. Todas as imagens subseqüentes possuem legendas nas duas línguas, português e inglês, não sendo a segunda necessariamente a tradução da primeira. Às vezes, tais legendas são bastante diversas, como no caso de um outro panorama da movimentada Avenida Borges de Medeiros. A legenda em português salienta: "O

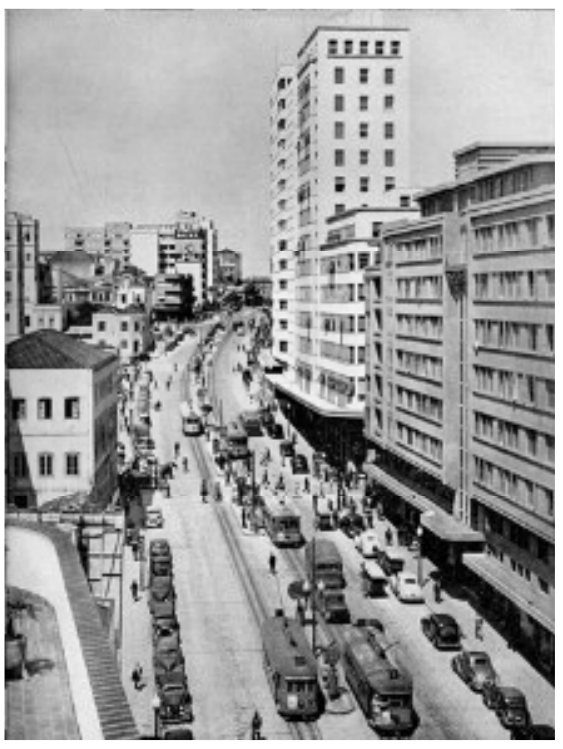
primeiro 'arranha-céu', na embocadura da avenida Borges de Medeiros"; já a legenda em inglês indica, simplesmente: “A busy corner". A legenda em inglês parece descrever melhor a fotografia: bondes, carros e pedestres cruzam uma esquina movimentada. $\mathrm{O}$ único edifício alto que aparece está ao fundo do quadro, deslocado, não sendo elemento central da composição - ao contrário do que a legenda em português salienta. Note-se que as duas imagens que representam a Borges de Medeiros são bastante próximas - o prédio realçado

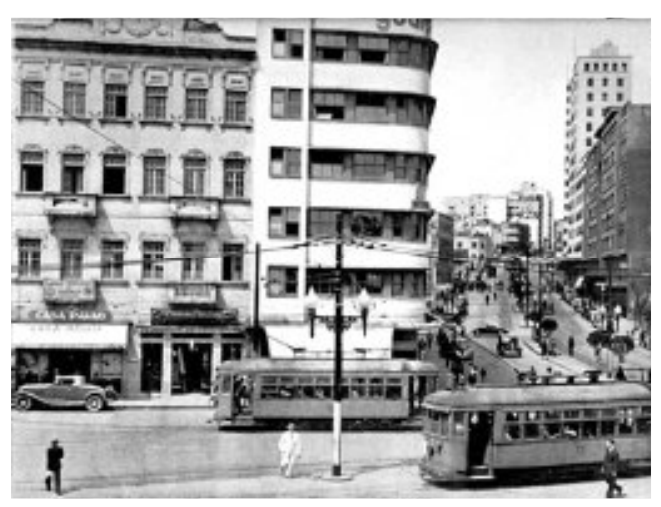
nas legendas é o mesmo -, variando somente a posição do fotógrafo diante da paisagem e, consequentemente, o ângulo de representação da rua. Se, na primeira o observador é alçado sobre a cidade, a partir de um enquadramento em que vêse a rua desde o alto, na outra é colocado dentro da agitada esquina. Há, ainda, uma terceira imagem da Borges de Medeiros, em que se retrata o movimento no viaduto da rua Duque de Caxias, em que há um bonde sobre o equipamento urbano e outro sob o mesmo.

Diversas imagens apresentam detalhes ornamentais de praças e áreas verdes da cidade, sempre com grandes edifícios ao fundo. Algumas dessas imagens são de leitura menos óbvia, contendo, por exemplo, elementos pouco iluminados em primeiro plano que 
acabam por configurar rebuscadas molduras para as paisagens que temos ao fundo. Muitas salientam o tecido da cidade em verticalização.

Quanto a diagramação das imagens, deve-se salientar que, aquelas que mostram paisagens e vistas amplas sobre a cidade são dispostas de modo a ocupar a maior porção da página possível. Mesmo as imagens horizontais (no formato paisagem) são dispostas na página no sentido vertical, de

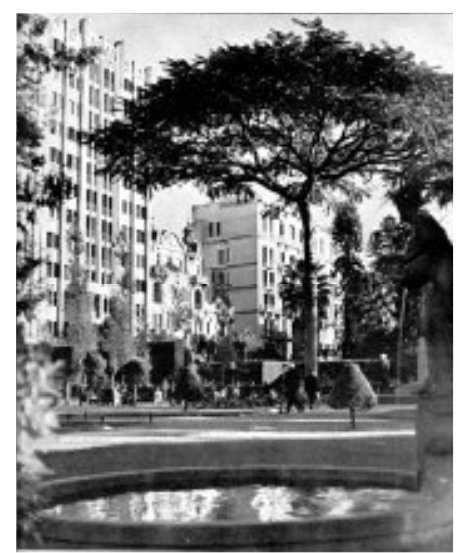
modo que o leito é obrigado a girar o livro para lê-las. Há uma fotografia panorâmica do centro da cidade que, sozinha, ocupa duas páginas.

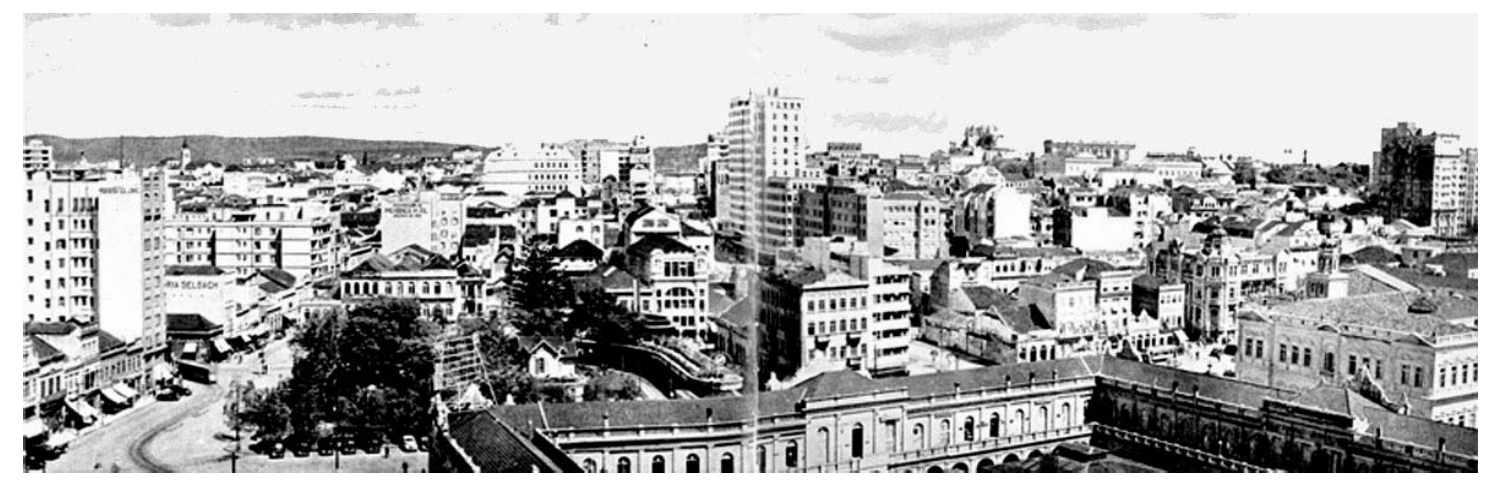

As imagens de prédios históricos, Igrejas e altos edifícios apresentam enquadramentos fechados. Ora, sabendo-se que o espaço do quadro é um campo significante que recorta a realidade (MACHADO, 1984), deve-se estar atento ao fato de que se exclui o que não convém à enunciação. Os enquadramentos fechados podem indicar a existência de elementos adjacentes ao referente que seriam incômodos para a imagem que
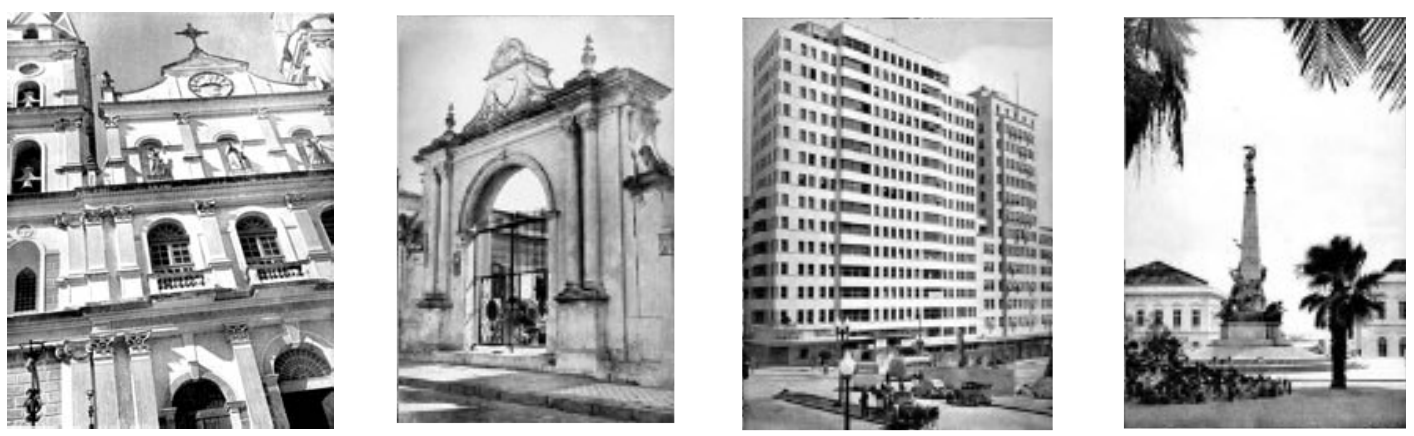
se buscava construir. Nessas imagens, poucas figuras humanas compõem os quadros, e quando estão presentes, surgem como pequenos detalhes insignificantes, transmitindo a sensação de que o fotógrafo buscou elimina-los, considerando-os elementos poluidores das feições monumentais dos prédios. Nesses casos, as esculturas e bustos presentes nas fachadas ganham mais destaque do que as pessoas que circulavam pelos locais retratados.

Quero chamar especial atenção a alguns conjuntos de imagens. A primeira delas é uma tomada panorâmica que mostra a vista dos altos da avenida João Pessoa em direção aos Campos da Redenção. Em primeiro plano, tem-se um edifício que, partido ao meio, cedeu espaço à avenida recentemente construída ou reformada restos de tijolos e sobras de construção tornam

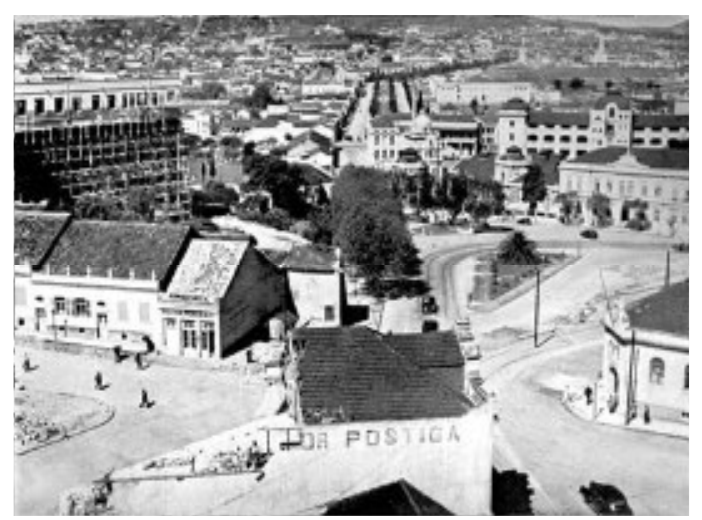
evidente uma obra recém finalizada. A legenda afirma: "onde o urbanismo corrige e moderniza velhos aspectos".

A mesma construção de sentido evidenciando o "progresso" através da imagem pode ser lida em duas fotografias que surgem em seqüência, comportando porém uma carga semântica oposta, evidenciando aspectos coloniais da cidade. Uma delas retrata em plano médio a Ponte dos Açorianos, composta com uma frondosa árvore. A legenda indica: Pôrto Alegre pitoresca: a velha ponte colonial sobre o riacho. A outra imagem mostra os casarios baixos e pequenos à margem do rio. Com suas paredes debruçando-se sobre as águas. Trata-se de uma vista que deixou de existir, na medida em que Loureiro da Silva

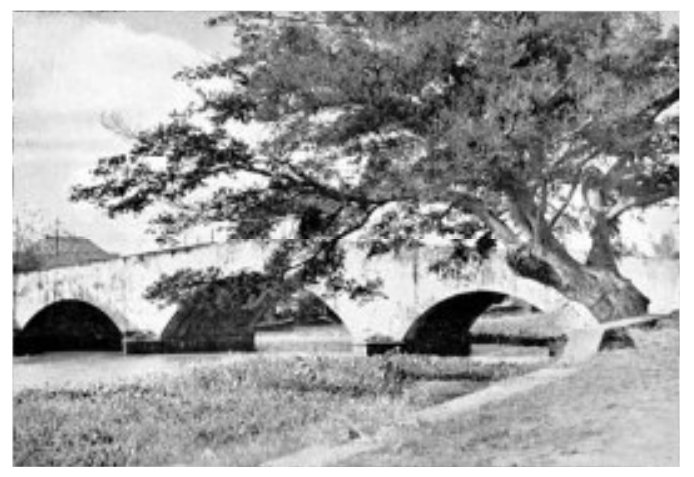
concretizou a retificação do arroio. A legenda indica: "um detalhe que passou para a história com a recente retificação do curso deste rio". Estas duas imagens em conjunto parecem evidenciar aspectos coloniais e pitorescos da cidade, alguns dos quais fadados ao desaparecimento iminente através da "força do progresso". 


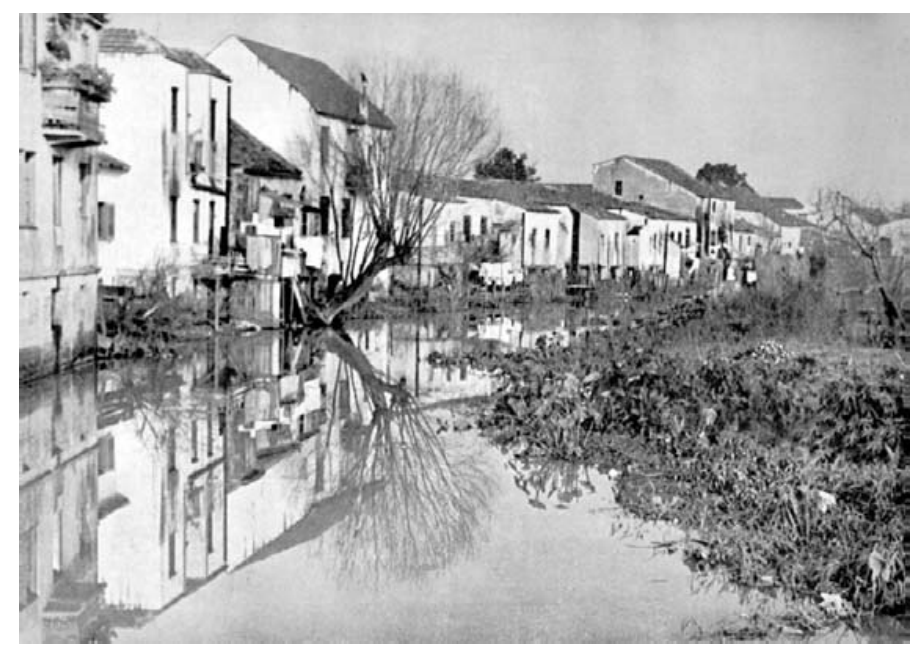

Quando, já nas porções finais do Álbum, a figura humana surge em primeiro plano, é comparada imageticamente à estátua de uma fachada com feições selvagens e indígenas: um homem de feições populares, com uma camisa simples e um cesto de vime sobre a cabeça. Essa primeira impressão parece demonstrar que o exotismo será o traço evidenciado na população retratada. E isso realimente se dá. Mostram-se imagens do mercado de frutas, em que barcos à beira do cais, montes de frutas, trabalhadores e cestas de vime compõem um aspecto exótico da cidade. Em uma página dedicada à feira, temos uma montagem em que se sobrepõe diversas fotografias, como uma bricolagem, que torna o aspecto do lugar ainda mais poluído. Nessa mesma montagem, um mesmo sujeito aparece seis vezes em diversas poses, nunca olhando para a câmera. E, na imagem que ocupa uma página interia, este mesmo homem está no centro do quadro. Há outras montagens do mesmo tipo tratando de diversos assuntos, sempre relativos à escala humana: esportes, esportes, trabalho fabril, uma banda marcial. As pessoas, assim, geralmente surgem em contextos em que se sobrepõem inúmeras fotografias. Ao lado de uma dessas montagens, a paisagem bucólica de uma

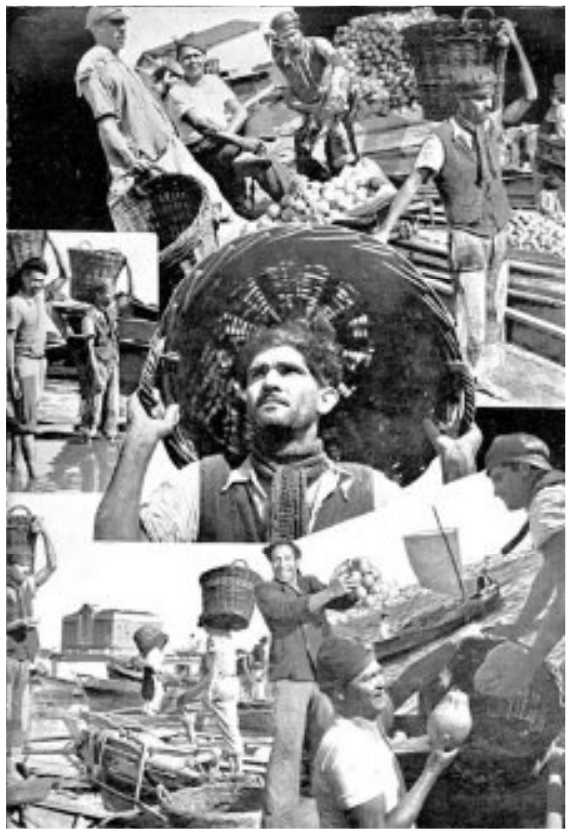
praia do lago Guaíba ocupa uma página inteira. 
Há muitas fotografias retratando a paisagem de Porto Alegre - tanto rural quanto de áreas centrais. Quando aparecem pessoas retratadas, as imagens são de exostismo. Mostra-se brigas de galo (duas páginas interias), trabalhadores populares, pescadores artesanais, uma gaúcha pilchada montada à cavalo manejando um laço e etc. As exceções são o retrato de meninas uniformizadas saindo do colégio, um grupo de universitários e trabalhadores da construção civil (sendo que a legenda afirma: "Dois objetivos do Estado Novo: Educação e Estradas). Quando se mostram as atividades esportivas, a ênfase recai sobre o movimento; a figura humana, nesse caso, torna-se bastante reduzida em comparação com o espaço reservado às paisagens. Se observamos as imagens como um todo, percebemos que se enfatiza o crescimento urbano, a verticalização da cidade, os viadutos e avenidas, porém busca-se retratar também as feições exóticas e pitorescas de Porto Alegre.
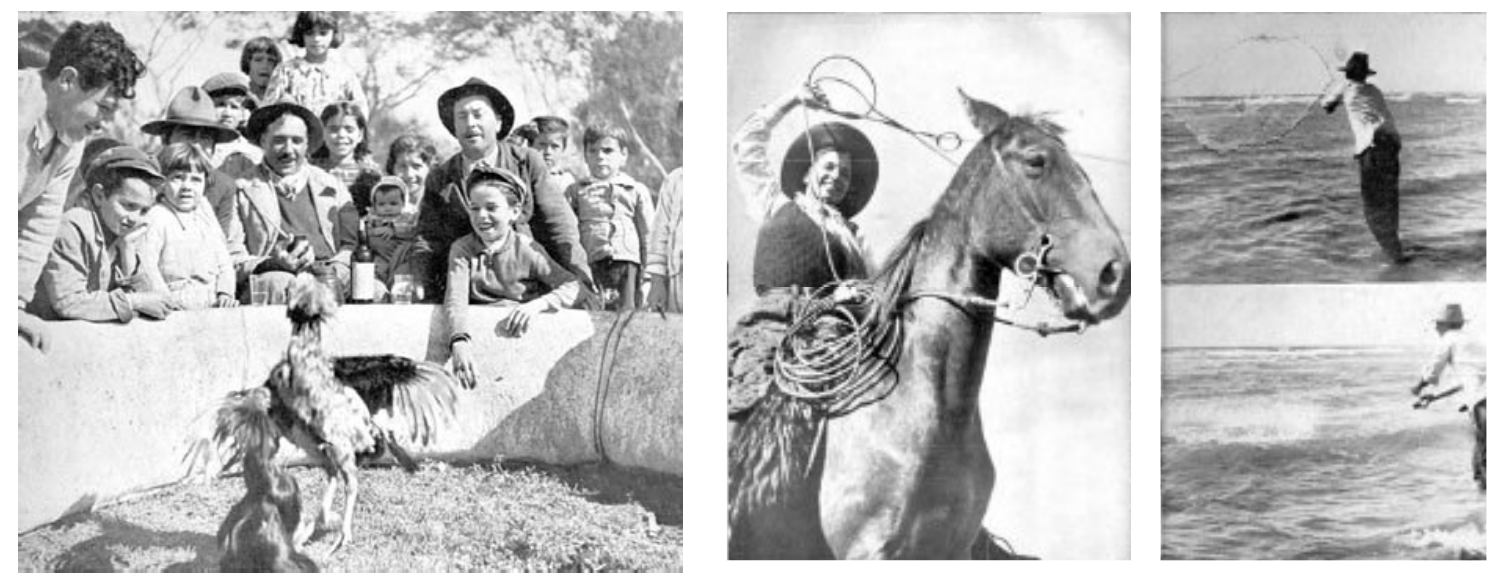

Boris Kossoy, em um capítulo de sua obra "Realidades e ficções na trama fotográfica" ${ }^{17}$ aborda a construção do nacional no período imperial através da análise de uma série de imagens contidas no Album Vues du Brésil, organizado pelo Barão do Rio Branco para ser lançado na França, no fim do governo de D. Pedro II - pouco antes de ser proclamada a república e ser extinto o regime imperial brasileiro. Estando consciente de

\footnotetext{
${ }^{17}$ Idem, Parte 2: A construção do Nacional na fotografia Brasileira: o Espelho Europeu, págs. 73 a 125.
} 
que se tratava de um outro contexto social, e que as imagens contidas no álbum poderiam adquirir diferentes significações conforme o olhar de época - questões que fogem à alçada do presente estudo -, o trabalho de Kossoy serve como um norteador para a análise aqui desenvolvida sobre o livro "Porto Alegre, Retrato de uma Cidade". No caso dessa obra, não se trata de uma produção exclusivamente voltada para o público europeu, como o Vues $d u$ Brésil, porém o fato de todas as fotografias conterem legendas em inglês demonstra que o retrato de Porto Alegre também se destinava a um público estrangeiro. No caso do Vues, trata-se da construção de uma imagem de Brasil, e portanto algo extremamente mais amplo do que o retrato de Porto Alegre que o álbum aqui analisado pretende traçar. Há, no entanto, elementos da análise de Kossoy que fornecem ferramentas para interpretar o conjunto de imagens apresentadas até aqui. O que mais contribuía, segundo o autor, para a construção do nacional no Álbum eram, como no caso do Retrato, cenas de progresso material e avanços técnicos (estradas de ferro, transformações urbanas, industrialização, obras de construção civil e etc.), que se encontram mescladas à imagens do exotismo do Brasil e das formas de vida social na cidade. Cenas de natureza exuberante e expedições exploratórias, no Vues du Brésil, uma vez que se buscava construir uma idéia genérica da totalidade do país; já no Retrato, as imagens do progresso, conforme afirmamos, são compostas a partir de tipos populares da capital gaúcha, cenas de trabalho (cabe lembrar que uma das características mais marcantes do Estado Novo foi a exaltação do trabalho, além da intensa busca de industrialização), de montaria e manejo de laço (por uma mulher), de aspectos pitorescos e coloniais tais quais as casas à beira do riacho e a Ponte dos Açorianos, de fazeres lúdicos exóticos como a briga de galos.

As imagens da modernização do País, como sugere Kossoy, e se percebe tanto no Vues $d u$ Brésil quanto no Retrato, foram amplamente exploradas pelas elites dirigentes, no sentido de se divulgar uma leitura dirigida acerca da realidade de cidades e do país. De acordo com Kossoy, este tipo de álbum possuía fundamentalmente uma finalidade promocional, propagandística. O Vues, na análise conclusiva do autor, buscava desfazer a imagem de um Brasil atrasado social e moralmente, substituindo-a por uma idéia de civilização e progresso. Já em relação ao Retrato de uma Cidade, acredito que a tentativa de divulgar imagens de uma cidade que crescia e se metropolizava é evidente, visto que são abundantes as imagens de amplas avenidas, arborizadas e ornamentadas praças e parques, 
suntuosos prédios públicos, majestosos viadutos, além de mostrar obras sendo realizadas, o trabalho operário e etc. Entretanto, às imagens do progresso material da cidade são adicionados retratos de pessoas vestidas com típicos trajes relacionados à tradição gaúcha, de fazeres, de exóticos mercados de frutas onde trabalhadores carregavam as cargas e cestos de vime equilibrados sobre suas cabeças, de palafitas construídas nos alagados territórios das "ilhas fronteiriças", das pequenas casas construídas às margens do tortuoso Arroio Dilúvio (imagem anterior às obras de canalização, já iniciadas quando do lançamento do livro), bem como de antigos ornamentos coloniais da cidade. Estas imagens, que transmitem a idéia da persistência de feições tradicionais de Porto Alegre, ao meu ver remetem ao argumento central da tese de Charles Monteiro ${ }^{18}$ : em épocas caracterizadas por um tempo acelerado em direção ao futuro, onde levava-se a termo grandes transformações urbanas, sociais, políticas e econômicas, emerge, por parte da população desorientada face a drásticas mudanças na vida urbana, uma demanda de memória, a necessidade de releitura do passado. E as imagens tradicionais de Porto Alegre, a meu ver, são exploradas justamente no sentido de ressaltar antigos aspectos convivendo com feições estéticas modernas. Se esse conjunto de imagens pudesse ser substituído por uma frase, ao meu ver esta frase seria: "Veja, a cidade está se transformando; porém, sem deixar de ser o que era, sem se esquecer de seu passado".

\section{A modernização das Cidades Coloniais}

Creio que sejam óbvias as referências às experiências européias nos desejos de reordenação da ocupação territorial em Porto Alegre; conforme cita De Grandi, As "Elites clamavam nos jornais por reformas, por melhores e mais belas vias de acesso, pela modernização dos transportes [...] Pregava-se enfim a criação de uma nova ordem, que afastasse do centro das cidades os pobres, o mundo da malandragem e do crime, e que impusesse a beleza e a higiene para uma convivência feliz, alcançando assim a verdadeira 'modernidade', aquela que experimentava Paris sob Haussmann e que a transformou no símbolo duma época..."19. Se Porto Alegre, diferente de Paris, não teve um passado medieval a ser banido através da construção de uma nova ordem espacial proposta por

\footnotetext{
${ }^{18}$ Idem.

${ }^{19}$ SOUZA, Célia Ferraz de. Trajetórias do urbanismo em Porto Alegre - 1900 - 1945. In: DE GRANDI, Celito de.. Loureiro da Silva: o charrua. Porto Alegre: Literaris, 2002. p. 96.
} 
intelectuais iluminados pelas razões técnicas e científicas, teve um passado colonial a ser superado, pois remetia a uma situação de arcaísmo e atraso.

As referências aos modelos estrangeiros (europeus) de modernização para construção de uma nova civilização são bastante nítidas. Segundo Sérgio Buarque de Holanda $^{20}$, a construção da "civilização nos trópicos" foi resultado da tentativa européia de implantação de sua cultura em um vasto território, incluindo formas de convívio, instituições e idéias trazidas para as Américas e outras regiões colonizadas pelas nações européias. E, no caso das reformas urbanas, não nos afastamos desse processo - a busca de implantação da cidade moderna nos trópicos implica em instaurar novas regras de vida coletiva no Brasil e novos arranjos sociais. Segundo Rocha ${ }^{21}$, através da urbanização e da industrialização, buscava-se o progresso na ordem. È fato que o modelo europeu foi uma constante nas reformulações da trama urbana das grandes cidades brasileiras - o que fica expresso no caso de Porto Alegre: Loureiro da Silva, respondendo às necessidades de estudos para a elaboração de um plano diretor das reformas urbanas da capital gaúcha buscou, no Rio de Janeiro, o arquiteto Arnaldo Gladosh, antigo colaborador e seguidor de Alfred Agache, urbanista francês trazido na década de 1930 à capital federal e também a Porto Alegre para realizar estudos e propor projetos de renovações urbanas ${ }^{22}$. Sendo a vida urbana uma das características da civilização ocidental moderna, o impulso de fundação de cidades no "novo mundo" foi uma das principais ambições do colonialismo europeu. Entre os vários países colonizadores, entretanto, houve diferenças significativas.

Conforme afirma Sérgio Buarque de Holanda, a coroa portuguesa investiu numa primazia da vida rural, tendo se preocupado menos em "construir, planejar e plantar alicerces, do que feitorizar uma riqueza fácil e ao alcance da mão"23 $\mathrm{O}$ Brasil colonial caracterizou-se, como sabemos, por uma exploração litorânea, havendo pouca habitação urbana, enquanto outras potências colonizadoras, como a Espanha, garantiam a dominação justamente através da construção de cidades. Comparando as colonizações espanhola e

\footnotetext{
${ }^{20}$ HOLANDA, Sérgio Buarque de. Raízes do Brasil. Rio de Janeiro: Livraria José Olímpio Editora. 1956.

${ }^{21}$ ROCHA, Ana Luiza Carvalho da. As figurações de lendas e mitos históricos na construção da Cidade tropical. Iluminuras: Série do Banco de Imagens e Efeitos Visuais, número 34. Porto Alegre: BIEV, PPGAS/UFRGS, 2001. 15 p.

${ }^{22}$ Cabe dizer que Agache, trazido por Alberto Bins, traçou vários planos não realizados, porém mudou os rumos do planejamento urbano, tanto no Rio de Janeiro quanto em Porto Alegre. Entre os projetos de Agache que foram realizados na capital gaúcha está o Parque Farroupilha, levado a termo por Loureiro da Silva quase conforme a proposta inicial , produzida na década de 1930.
} 
portuguesa, a primeira caracterizou-se pela construção de cidades, preferencialmente no interior e em regiões altas, a partir de linhas retas, construindo-se ruas que não se modelavam pela sinuosidade do terreno e aspereza do solo; prevaleceu o "triunfo da aspiração de ordenar e dominar o mundo conquistado" 24 através do traço retilíneo da trama urbana, direção burocrática a um fim previsto. Ao redor de uma praça quadrangular inicial, os espanhóis definiam o traçado das futuras ruas.

Os portugueses, ao contrário, pautavam a colonização sobretudo na exploração comercial; sendo a colônia um lugar de passagem, fixavam-se na zona litorânea e tropical. Por conta de prevalecer a obtenção de proveitos para o Estado português e não o intuito de fundar uma nação, as cidades foram construídas junto ao mar e aos rios pela facilidade de navegação para o transporte de mercadorias. Assim, nos núcleos urbanos brasileiros as ruas e habitações eram construídas sem determinações expressas por parte da coroa, sendo as casas irregulares e desalinhadas dispostas segundo o capricho dos moradores. Aqui, conforme Holanda, se obedeceu às sugestões topográficas, já que os portugueses não planejavam nem traçavam fins e objetivos. Prevaleceu, entre eles, a rotina em detrimento às razões abstratas. "A cidade que os portugueses construíram na América não é produto mental, não chega a contradizer o quadro da natureza, e sua silhueta se enlaça na linha da paisagem"25. A partir da oposição entre as experiências coloniais espanhola e portuguesa, no que tange à fundação das cidades coloniais, Holanda sugere uma interessante metáfora: pela razão e minúcia que pautavam a criação das cidades em colônias espanholas, estes seriam ladrilhadores; os portugueses, que apostavam no acaso e seguiam a rotina ao invés da razão seriam semeadores de cidades.

Assumo aqui à metáfora sugerida por Sérgio Buarque de Holanda para refletir sobre o processo de formação de Porto Alegre. Conforme se desenvolve esta cidade, que acompanhava em sua trama viária as sugestões de um terreno cheio de morros e baixadas com o complicador de o centro insular ser limitado pelas águas do lago Guaíba - emergem grandes dificuldades de domesticação de seu crescimento, dificuldades estas enfrentadas pelas autoridades que assumiram a tarefa de reordenação de seu território urbano, necessidade técnica que aumenta em importância quando adentra-se o séc. XX. E é essa a

\footnotetext{
${ }^{23}$ Idem, p. 125.

${ }^{24}$ Ide, p. 127.

${ }^{25}$ Idem, p. 152.
} 
tarefa que Loureiro da Silva assume, dando prosseguimento às realizações de Otavio Rocha. Buscando eliminar as feições da Porto Alegre colonial, então tida como atrasada, imunda e subdesenvolvida, visava produzir o crescimento, a civilização iluminada pelas luzes das razões científicas. Buscando, conforme De Grandi ${ }^{26}$ "construir a mais bela cidade", Loureiro da Silva iniciou grandes obras estruturais, além de realizar estudos e propor um plano diretor para o desenvolvimento de Porto Alegre, guiando-se pelo Plano Maciel, primeira elaboração planejadora no sentido de controlar o antes desleixado (no sentido trazido por Holanda, de deixar estar) crescimento urbano.

\section{Reflexões finais}

Voltando à questão proposta no início deste estudo, creio que amar uma cidade e adorar ver os riscos do planejador sobre ela, conforme afirmou Loureiro da Silva, significa aderir ao processo de construção da civilização nos trópicos. Segundo Eckert e Rocha, “...mediante a destruição de estruturas espaciais que sinalizam um arcaísmo, os habitantes da cidade valorizam o presente na reformulação do passado" ${ }^{, 27}$. E isso explica, ainda conforme as autoras a "incompreensível adesão dos habitantes ao sacrifício de destruição das cidades brasileiras" ${ }^{28}$.

Ao se levar a termo grandes transformações infra-estruturais que modificavam completamente a própria paisagem da cidade, certamente se provocava o desenraizamento de populações urbanas. Para sanar esta desorientação, foram instauradas, pela administração municipal, políticas de gestão de memória - entre as quais a manipulação do impasse da historiografia oficial, através da modificação da definição da data de fundação de Porto Alegre, com vistas a se comemorar o bi-centenário da cidade durante um governo que a transformava profundamente. E parte das comemorações foram feitas através do lançamento de livros que divulgavam novas matrizes explicativas da historia oficial da cidade. No caso do livro "Porto Alegre, Retrato de uma Cidade", se construiu um material que, através de breves escritos e abundantes imagens, revia o passado da cidade, ressaltava certos aspectos de seu presente e projetava seu futuro. A mensagem central do livro é, ao

\footnotetext{
${ }^{26}$ Idem.

${ }^{27}$ ECKERT, Cornelia e ROCHA, Ana Luiza Carvalho da. A retórica do mito do Progresso, 'Brasil, um país sem memória!'. Iluminuras: Série do Banco de Imagens e Efeitos Visuais, número 7. Porto Alegre: BIEV, PPGAS/UFRGS, 2000. 17f. P. 5.
} 
meu ver, a de que a cidade se transformava, sem no entanto deixar de ser o que era. Construir uma cidade moderna, ou a mais bela das cidades, não necessariamente implicava em apagar todo o seu passado e esquecer suas tradições, mas demandava toda uma resignificação destes elementos.

\section{REFERENCIAS:}

ACHUTTI, Luiz Eduardo Robinson. Fotoetnografia: um estudo de antropologia visual sobre cotidiano, lixo e trabalho; Porto Alegre: Tomo Editorial; Palmarinca, 1997.

BACHELARD, Gaston. A Dialética da Duração; São Paulo: Ática, 1988.

BAXANDALL, Michel. O olhar renascente - Pintura e experiência social na Itália da Renascença. São Paulo: Ed. Paz e Terra, 1991.

BRANDÃ̃, Carlos R. Territórios do Cotidiano: uma introdução a novos olhares e experiências; Porto Alegre/ Santa Cruz do Sul: Ed. Universidade/UFRGS / Ed. Universidade de Santa Cruz do Sul/UNISC, 1995.

DE GRANDI, Celito. Loureiro da Silva: o charrua. Porto Alegre: Literaris, 2002.

ECKERT, Cornelia e ROCHA, Ana Luiza Carvalho da. A retórica do mito do Progresso, 'Brasil, um país sem memória!'. Iluminuras: Série do Banco de Imagens e Efeitos Visuais, número 7. Porto Alegre: BIEV, PPGAS/UFRGS, 2000. $17 \mathrm{f}$.

KOSSOY, Boris. Realidades e Ficções na Trama Fotográfica. Cotia: Ateliê Nacional, 1999.

HOLANDA, Sérgio Buarque de. Raízes do Brasil. Rio de Janeiro: Livraria José Olímpio Editora. 1956.

KOSSOY, Boris. Realidades e Ficções na Trama Fotográfica. Cotia: Ateliê Nacional, 1999.

LE GOFF, Jacques. História e Memória. Campinas: Editora da UNICAMP, 1994.

MACHADO, Arlindo. A Ilusão Especular: Introdução à fotografia. São Paulo: Brasiliense, 1984.

MELLO, João Baptista Ferreira. Dos Espaços da Escuridão aos Espaços de Extrema Luminosidade - O Universo da Estrela Marlene como Palco para a Construção de Conceitos Geográficos. Tese de Doutorado em geografia, UFRJ. Rio de Janeiro: UFRJ, 1997.

MONTEIRO, Charles. Porto Alegre e suas escritas - histórias e memórias. Tese de Doutorado em história. PUC-SP: São Paulo, 2001.

OLIVEIRA, Clóvis S. Porto Alegre e sua Formação; Porto Alegre: Metrópoles, 1993.

PORTO ALEGRE, Achylles. História Popular de porto Alegre, 1911

ROCHA, Ana Luiza Carvalho da. As figurações de lendas e mitos históricos na construção da Cidade tropical. Iluminuras: Série do Banco de Imagens e Efeitos Visuais, número 34. Porto Alegre: BIEV, PPGAS/UFRGS, 2001.

ROCHA, Ana Luiza Carvalho da. A Irracionalidade do Belo e a Estética Urbana no Brasil; In: MESQUITA, Zilá e

SANTOS, Carlos Nelson Ferreira dos e VOGEL, Arno (coord.). Quando A Rua Vira Casa: a Apropriação dos Espaços em um Centro de Bairro; Convênio IBAM/FINEP. $2^{\mathrm{a}}$ ed. revisada e atualizada. Rio de Janeiro, 1981.

SCHARF, Aaron. Arte y Fotografía. Madrid: Alianza Editorial, 1994.

\footnotetext{
${ }^{28}$ Idem, p. 6.
} 


\section{FONTES DE PESQUISA:}

SPALDING, Walter (coord.). Porto Alegre, Retrato de uma Cidade. Departamento central dos Festejos do Bicentenário. Porto Alegre: Of. Graf. Da Livraria do Globo, 1940.

SPALDING, Walter (coord.). Porto Alegre Biografia Duma Cidade. Departamento central dos Festejos do Bicentenário. Porto Alegre: Of. Graf. Da Livraria do Globo, 1940. 